\title{
Optimizing cost-efficiency of long term monitoring programs by using spatially balanced sampling designs: The case of manila clams in Arcachon bay
}

\author{
Kermorvant Claire ${ }^{1,{ }^{*}}$, Caill-Milly Nathalie ${ }^{2}$, Bru Noëlle ${ }^{1}$, D'Amico Franck ${ }^{1}$
}

${ }^{1}$ CNRS/UNIV PAU \& PAYS ADOUR/E2S UPPA, Laboratoire de Mathématiques et de leurs Applications de Pau - MIRA, UMR5142, 64600 Anglet, France

2 IFREMER, Laboratoire Environnement Ressources d'Arcachon (PDG-ODE-LITTORAL-LERAR) - FED 4155 MIRA, 64600 Anglet, France

*Corresponding author : Claire Kermorvant, email address : claire.kermorvant@univ-pau.fr

\begin{abstract}
:
Funding lake is one major issue in ecology, in particular at local scale. It is known that sustainable management of a natural population requires a good understanding of its functioning, itself dependent on a good long term monitoring program. Such programs are usually very difficult to implement, especially for resources characterized by high spatio-temporal variation in their distribution, resulting in a trade off between efficiency and costs. Today, thanks to rapidly evolving statistical theory, new survey designs are developed, some with the characteristic of well balancing samples in the study area. This paper aims at demonstrating that theses advanced sampling designs perform better than the usual ones for long term monitoring program of local resources, with the added benefices of saving money and also increasing results accuracy. To prove it, and for it high spatio-temporal variation in it distribution, we choose the example of Manila clam's stock monitoring in Arcachon bay. This stock is under high scrutiny and last campaigns could not be done because of lack of funding (at least 50,000€/survey). We use a simulation study based on real data to assess and compare performances of news and older sampling designs on this survey. Three sampling designs are tested in both of the 6 past monitoring campaigns data and we estimate the cost of their application in the field. Selected sampling designs are: 1 - simple random sampling (SRS - the one used in the past years of this monitoring program), 2 generalized tessellation sampling (GRTS - a recent spatially balanced sampling design known for its high performance) and, 3 - balanced acceptance sampling design (BAS - a newly developed spatially balanced sampling design, never tested yet in a real population). We first confirm that the two spatially balanced sampling designs perform better than simple random sampling. Both of the advanced sampling designs perform equally and allow achieving same accuracy in the results with almost half sampling intensity than SRS. This makes them so cost-effective that $30 \%$ of each campaign price could be saved if they were used. Moreover, the three sampling designs need a constant sample size thought years to achieve a fixed accuracy in results. This will permit us to fix one sample size that could be done for all future campaigns; and this, despite the existence of spatial and temporal variations in clam's distribution.
\end{abstract}




\section{Highlights}

- Long term monitoring program at local scale are mandatory for resource management but often too expensive to undertake. For the example of manila clams resource in Arcachon bay, each campaign price can be lowered by $30 \%$ only in using spatially balanced sampling design instead of simple random sampling. More than lowering the survey price, wanted accuracy in the results can be fixed a priori. - BAS sampling design, never compared to other sampling designs in real data previously perform very well.

Keywords: Arcachon bay, Balanced acceptance sampling, Spatial sampling, Spatial variation, Temporal variation, Virtual ecology 


\section{Introduction}

Most of ecological studies involve spatial or temporal data, even both of them. But performing an exhaustive survey of any phenomenon is almost impossible or may prove to be tricky (Chiarucci et al. 2003; MacKenzie 2006) because of time (Cox et al. 1997) and/or money lack (Theobald et al. 2007; Jackson et al. 2008; Lazarina et al. 2014). The common practice for dealing with this problem is trying to infer the targeted phenomenon on the basis of samples from the original population (Mackenzie 2006). Results of theses sampling procedures are more and more accurate when sample size increases. But the sampling procedure costs increases also according to the sample size. There is a trade-off between the results accuracy and the cost of the survey. A good resource management involves a good knowledge of the population of interest, and also accurate results in sampling procedures. But, when it comes to reality, especially at local scale, funds devoted to ecological studies are usually unsubstantial and far from being large enough to get accurate estimates. In this study, we want to illustrate that local scale long term monitoring program could be optimised (meaning in the context of our study being less expensive but providing a better accuracy) only by changing the survey design. In this respect, we choose to apply our methodology on manila clam long term monitoring in Arcachon bay.

Manila clam (Venerupis philippinarum) is one of the five highest produced bivalves in the world (Astorga 2014) with 4010702 T produced in 2014 (source : Fao FishStat). It is worldwide present and economically important for fisheries industries. In many countries, bivalve s are harvested for food and baits (McLachlan et al. 1996). But stocks are of concern in many locations. Numerous studies around the world on natural populations were undertaken with the aim to assess the geographic spread of this species (which can be invasive), in Poole Harbour in UK (Jensen et al. 2004), San Francisco Bay (Carlton et al. 1990), Venice Lagoon (Pranovi et al. 2006), Southern California (Talley et al. 2015) and in Santander Bay, Spain (Bidegain et al. 2015). Other studies were carried out to further 
understand the influence of factors associated with mortality in manila clam stocks (Park and Choi 2001; Paillard et al. 2004; Dang et al. 2009, 2013), to study hyperparasites (Le et al. 2015), and to report micro plastics ingestions (Davidson and Dudas 2016).

Arcachon bay is a $156 \mathrm{~km}^{2}$ semi-sheltered lagoon located in the southwest coast of France. It represents, with the Morbihan Gulf, the main manila clam production area for this country. Manila clams are studied in Arcachon bay for the purposes of following descriptors of the stock, assessing its status and proposing an adapted management plan of this resource to the fishermen (comanagement process between scientists and professional fishermen). Not only fishermen request and order the survey but they also help scientists during field procedure; in turn, scientists suggest improved management solutions to fishermen.

The first survey was undertaken in 2003 (Caill-Milly et al. 2003) and subsequently carried out every two years since 2006 (Caill-Milly et al. 2006, 2008; Sanchez et al. 2010, 2012, 2014). A stratified random sampling (StRS) was applied on 17 strata, with a sampling effort of 10 stations per $\mathrm{km}^{2}$ (this sampling effort is an empirical compromise between field expertise, biological information and available fund); each sampling station being identified by their geographic coordinates. A major concern with this monitoring survey, given that sampling effort, is that it is time consuming (approximately 500 sample stations are visited on each survey) and costly, although the aim is to keep the survey costs under a threshold of 50K€. Without the support (financial and in kind) of fishermen, ongoing surveys are not assured. This indeed happened in 2016 and 2017 when no surveys were undertaken. This lack of data in 2016 and 2017 rose new problems, both for statistical and management reasons, because it broke the time series of stock's status indicators and impeded sustained effort in identifying population best management measures (e.g. restricted harvesting areas and periods, limited licenses number). Indeed, the Arcachon Bay monitoring survey is of particular socio-economical importance; for example, on the socio-economical point of view, there were 70 manila clam's professionals fishermen in 2016 (source: IFREMER personal communication). 
Therefore it has been crucial and urgent to consider alternative monitoring survey designs that will be less expensive without jeopardizing accuracy of estimates.

Clams are spatially structured species, patchily distributed in their living area (McLachlan et al. 1996; Dugan and McLachlan 1999; Defeo 2003; Denadai et al. 2005) and this pattern makes them challenging to sample (Gray 2016). Formers monitoring programs results in Arcachon bay confirm the patchy spatial structure of manila clams in this area, but also highlight a temporal variation of abundance and biomass between both campaigns (Sanchez et al. 2014). For bivalve distribution studies, as for the whole ecological studies (Smith et al. 2017), there are only few papers which indicates the used sampling design. Some of them use systematic design (Borja and Bald 2000; Bald and Borja 2001, 2005) and other random survey designs transects selected randomly in space and time (Wekell et al. 1994). For studying distribution of intertidal macrofauna including bivalve on beach, nested survey design with transects was also applied (James and Fairweather 1996). Stratified version of simple random sampling design was used for bivalve in the French Normano-Breton Gulf (Pitel et al. 2004), in Arcachon bay (Caill-Milly et al. 2003), in Morbilhan gulf (Berthou et al. 1997) and for exploited bivalve in the swash zone on exposed ocean beaches (Gray et al. 2014).

It was proved recently that some sampling designs show better performance for clam's studies (Kermorvant et al. 2017). Here, we define sampling design's performance as the minimum sampling intensity needed by a sampling design to reach a fixed accuracy in the results. As generally accepted, we consider that the lowest is the sample size for the sampling design, the highest its performance. Under this acceptation, a previous study based on one year of Arcachon bay's manila clam data showed that generalized random tessel lation sampling - GRTS (a variant of spatially sampling design) performs better than simple random sampling (SRS). As it allows obtaining a fixed accuracy with fewer samples, GRTS proves to be less expensive (and so more cost-effective) to use than SRS (Kermorvant et al. 2017). This conclusion was raised from a study based on a small dataset, limited to a one year-survey; it is important to definitely prove that this conclusion is robust and highly generic, encompassing any kind of spatially balanced design. The first aim of this study is thus to 
confirm that GRTS does perform better than SRS for manila clam monitoring despite natural interannual variability. To enlarge the picture, and conclude that any spatially balanced design can do better, we also aim at assessing performance of another spatially balanced sampling design, namely the balanced acceptance sampling (BAS) recently brought available (Robertson et al. 2013).

This is the first time that this new sampling design will be used to optimize a survey, and that it will be compared with other sampling designs in term of cost-efficiency.

As a corollary, , a second task we aim at bringing to life for practitioner in this paper is to address the existence of one sampling size by strata that give good estimates of abundance and biomass throughout a medium-term survey (here six years of manila clam monitoring data). And this, despite the existence of spatial and temporal variations in clams abundance and effectives. We argue that if such sampling size exists, it is then possible to propose the better sampling design that could be applied for the future field campaigns and provide managers and fishermen with the answer to the key question they all ask: how many samples have to be taken by strata to achieve a wanted accuracy in clam's biomass and abundance throughout the whole bay?

Beyond Arcachon bay manila clam population's specificities, other local populations throughout the world have to be surveyed with the same questions and limits (especially in terms of cost). The ultimate goal of our study is thus to explore transferability of the approach so that other monitoring programs could be optimised worldwide so that more cost-effective management of local resource can be made everywhere.

\section{Material and methods}

\subsection{Field survey}

The primarily area of location of V. philippinarum in Arcachon Bay was divided into 17 homogeneous strata (fig. 1) from expert knowledge (hydrological, sediment particle size characteristics, currents patterns, management point of view) (Caill-Milly et al. 2003) as expressed above. 14 strata are 
sampled since 2003, two (namely I and J strata) only since 2008, and one (namely RIO stratum) since 2012.

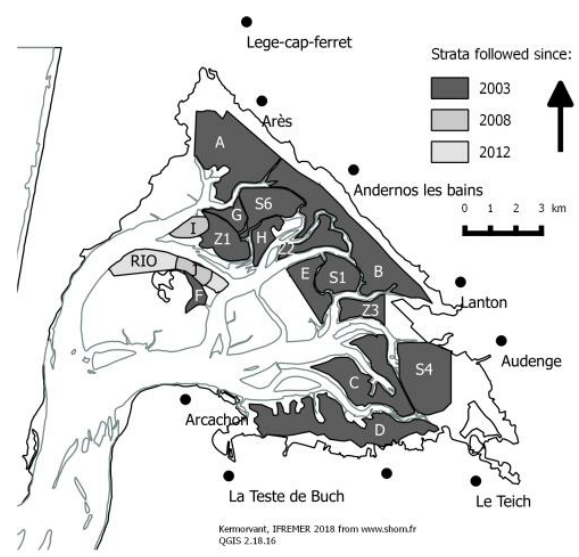

Fig. 1. The survey site divided into 17 strata (A, B... RIO... Z3)

The survey gear is a Hamon grab which collects a sediment core of $0.25 \mathrm{~m}^{2}(0.5 \mathrm{~m} * 0.5 \mathrm{~m})$ on a $0.2 \mathrm{~m}$ depth at the ebb tide. We assume that this measuring tool permits an optimal detection (the grab keep sediment deeper than the maximal deepness of clam burring). Therefore, it allows detecting clams distribution in the bay and its space-time variation without sampling bias.

\subsection{Data interpolation:}

The point data obtained during previous monitoring campaigns were used to recreate two maps for each survey year (one of abundance and other of biomass) for the whole bay. Geostatistics along with the statistical method of kriging, which permits guessing values of non-sampled points from the known value of their sampled neighbours were applied to the existing database rich of information on spatial distribution of abundance (expressed in number per $0.25 \mathrm{~m}^{2}$ ) and biomass (in gram per $0.25 \mathrm{~m}^{2}$ ) with the following steps:

1) variography analysis and auto-adjustment of a model to the experimental variogram (nugget effect and isotropic exponential model); 
2) geostatistical interpolation of data using the variogram model. The implemented interpolation method used was a block kriging model with a $200 \mathrm{~m}$ sliding neighbourhood.

These stages were carried out with R Software (R Core Team 2014), using the RGeostats package developed by the École des Mines of Paris (http://rgeos.free.fr/). Fig. 2 summarizes these different steps.
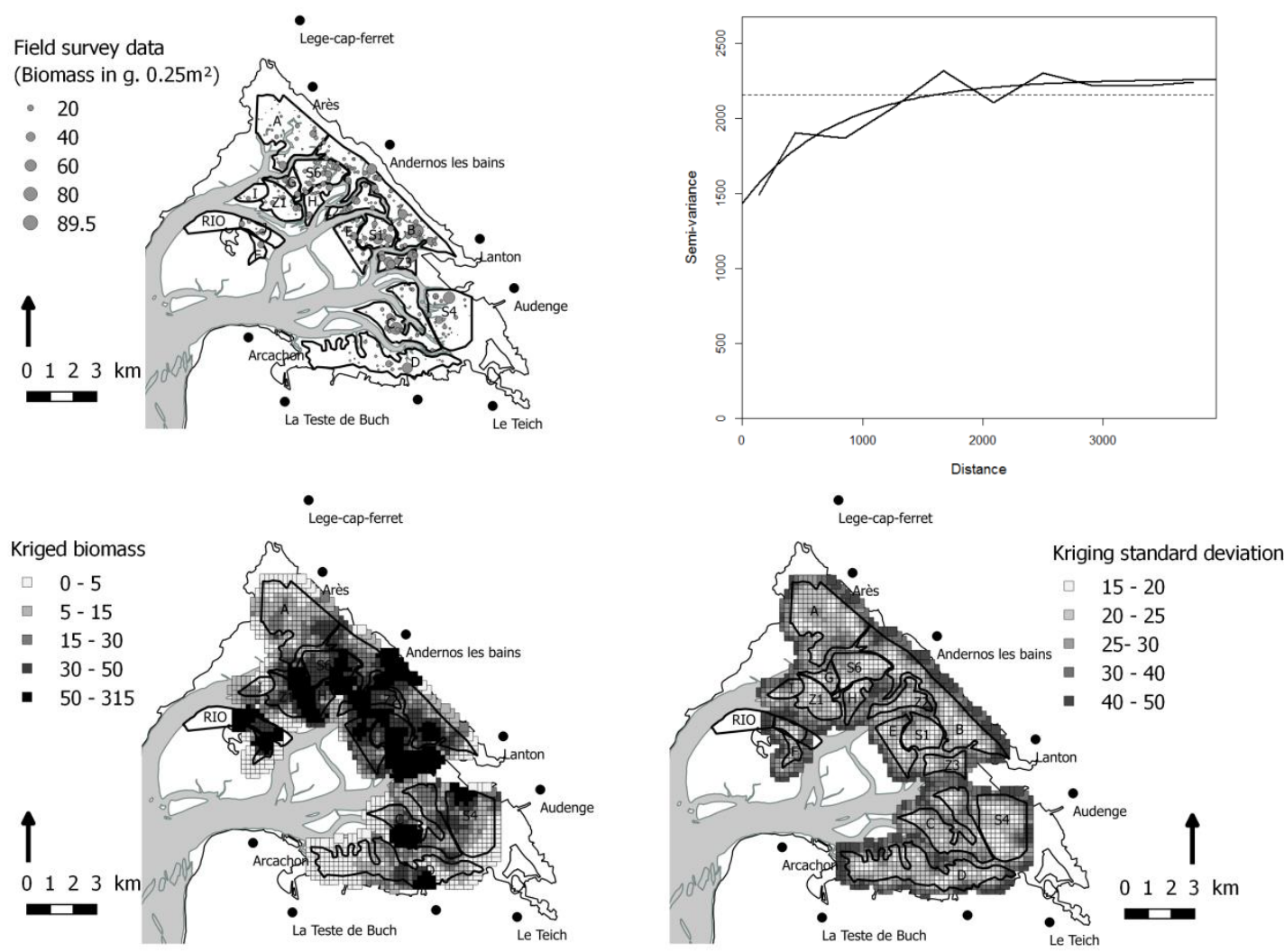

Fig. 2: Example of kriging procedure for biomass in 2010. Top-left - Survey samples positions and results for biomass, top-right - experimental semi-variogram (non-smoothed line) and modelled associated semi-variogram (smoothed line), bottom-left - kriging results and bottom-right - standard deviation associated to the kriging method.

Spatial distribution of abundance were interpolated from the data collected during the six survey campaigns (2003, 2006, 2008, 2010, 2012 and 2014) for both of the two estimates (biomass and abundance). These populations are herein called "semi-virtual populations" in the sense they 
represent the real phenomenon with an associated standard deviation and are used to compare the efficiency of sampling designs.

\subsection{The sampling designs to be compared: StRS vs GRTS vs BAS}

The basic survey design used in a 6 years survey in Arcachon Bay (stratified simple random sampling StRS) is compared to two spatially balanced survey designs: Generalized Random Tessellation Sampling (GRTS) known for its high efficiency, and the recent one Balanced Acceptance Sampling (BAS) whom efficiency is not fully assessed yet.

\section{SRS}

It is common ground that probability based survey designs are not enough used in ecology studies (Smith et al. 2017), but when used, simple random sampling (SRS) is the most common of them, certainly due to its ease of use and its flexibility. Additional samples can be easily added to the survey design a posteriori. The main disadvantage of SRS is that, sometimes, it exists cluster of samples or areas devoid of samples in the survey scheme (Stevens and Olsen 2004; Christianson and Kaufman 2016). A recent study (Christianson and Kaufman 2016) indeed underlines that random sampling can have particular spatial arrangement that over- or under-samples certain regions of the studied area and leads to larger survey error. This design can fail to detect spatial patterns so it can be inefficient for patchily distributed resource study (Yu et al. 2012). A variant of SRS is the spatial stratified SRS technique (called stratified random sampling-StRS) which involves dividing the study area in strata and then randomly sample within each stratum. For a better performance, strata must be created in order to be relatively homogeneous among themselves (Yoccoz et al. 2001) according to the studied phenomenon (Zhao et al. 2016).

The relatively new approach of spatially balanced survey designs appears to often create more efficient, flexible and rigorous monitoring designs (Theobald et al. 2007). Some studies demonstrate that using a spatially balanced design can be an advantage when the studied variable has spatial trend (Stevens and Olsen 2004; Theobald et al. 2007; Grafström et al. 2012; Grafström 2012; Grafström and Lundström 2013; Robertson et al. 2013) but none have tested it yet on spatially 
structured populations with temporal variations of lagoons areas. Hence, for this study, we choose GRTS and BAS designs as examples of spatially balanced survey designs.

\section{GRTS}

GRTS survey design is an unified survey approach adapted to the environmental monitoring at large scale and over long term (Stevens and Olsen 1999, 2003, 2004). It uses a spatially balanced al gorithm instead of a simple random one. This spatially balanced algorithm orders area statistical units in a line and then runs a reverse sequence function before selecting a sample with a systematic design. When the selected samples are reassigned to their original place in the area, they are spatially balanced. This leads GRTS to resemble in some ways the systematic survey strategy, despite actually surpassing it. This survey strategy is a true spatially balanced probabilistic design even if the distribution of samples is constrained in space. So, it allows design-based inferences to the entire study area. In addition, it provides the advantages that any point (site) in the target population is not too far from another sampling point, and very few sample points are found to be close. It allows freeing from one of the main disadvantage of simple random survey. As with SRS (and all others designs), the main area can be divided in homogeneous strata to be individually sampled. GRTS survey was used in several studies, for example to determine bull trout population status through counts in Basins of the Columbia River Plateau (Katz et al. 2013), or to develop survey ArcGIS tools through a case study of forest biodiversity survey in Hunan Province (Li et al. 2012, pp. 939-942). In this sense, GRTS is very relevant when it comes to draw units (sites) sampling of natural resources in the space because it allows to select spatially balanced samples. It was recently proved that clam monitoring in Arcachon bay can be GRTS considerably improved by GRTS in the basis of one-year data study (Kermorvant et al. 2017).

\section{$B A S$}

BAS is a newly developed spatially balanced sampling design (Robertson et al. 2013, 2017). It is an extension of the idea of GRTS where a Halton sequence is used to spread the samples across the study area. Study on BAS shown that it achieves a little better spatial balance than GRTS, but its main 
advantage is that it is faster to execute (Robertson et al. 2013) on computer. BAS could also be used in an area divided in strata. Very few scientific studies have already used it; one showed that BAS is superior to SRS in terms of spatial spread and precision on a crab population (Abi et al. 2017). One report already used a two dimensional BAS to survey bats in Bighorn Canyon National Recreation Area (BICA) (Keinath and NRA 2016) and show good results. We choose BAS as an example of spatially balanced sampling because it has the huge extra-advantage to balance the samples in three or more dimensions (representing for example latitude, longitude and altitude). This ability is particularly appropriate to monitor natural resources. A three dimensions survey is relevant for monitoring in water bodies (integrating deepness), and a four or more dimensions study design will be able to integrate information such as ecological threats, time intervals, species population structure, environmental data... (Brown et al. 2015). If we found that BAS perform well for manila clam's monitoring program in Arcachon bay with only two dimensions ( $\mathrm{x}$ and $\mathrm{y}$ coordinates), we could expect that it will perform even better with more dimensions.

\subsection{Defining optimal sample size by sampling design}

The first sample size which realizes the targeted accuracy is called "optimal sample size". To remove all possible hazardous bias in results, we use 1000 simulations of sampling efforts per year, per stratum and per estimates (biomass and abundance). It means that, for each year, each stratum and each estimate, 1000 simulations of 1 then 2 then $3 \ldots$ then $n$ stations selection were performed for both sampling designs. Accuracy on the results increases when the sample size increases.

We define then an optimal sample size for the whole bay according to the following steps:

1. For each stratum $\mathrm{i}$ and each year $\mathrm{j}$, let note $n_{i j}^{B}$ and $n_{i j}^{A}$ the optimal sizes for biomass and abundance respectively. Then keep $n_{i j}^{o p t}=\max \left(n_{i j}^{A}, n_{i j}^{B}\right)$ which represents the selected optimal size to study both the biomass and the abundance;

2. For each year $\mathrm{j}$, let $n_{j}^{o p t}=\sum_{i} n_{i j}^{o p t}$ be the total optimal sample size for this year. 
To be constant throughout the years, optimal sample sizes per campaign are compared only for the strata which were sampled all the studied years (thus excluding RIO, I and J strata).

This method allows choosing a level of accuracy that we want to achieve when sampling the semi virtual populations. In this study, we set the level of accuracy in biomass and abundance estimates to $10 \%$ (- see Supplementary materials for $5 \%$ and $20 \%$ levels results). So here, the optimal number of samples will be the minimal number of samples needed by a sampling design to achieve at least $10 \%$ of accuracy in biomass and abundance estimates.

Optimal samples sizes are firstly compared by years to detect temporal variation. Autocorrelation functions (ACF) and partial autocorrelation functions (PACF) are calculated with $\mathrm{R}$ software for both of the sampling designs. They allow to know if a value at a $t$ time is correlated to the previous value $t$ 1, and involve detecting temporal correlation in our optimal sample sizes. If these functions show that there is no temporal correlation in optimal samples sizes obtained throughout the 6 studied years, this means that the assessed sampling design is able to deal with temporal variation of the clam distribution. In this case we could set a fixed number of samples to do by years for future campaigns to achieve $10 \%$ of accuracy in results. Secondly, using a non parametric paired WilcoxonMann-Whitney statistic test, optimal sample sizes are compared between strata to know if there are differences between both sampling designs results at this scale. This information tells if one or other sampling design perform better than the others.

\subsection{Optimizing the design and assessing the monitoring cost}

To optimize the survey design, it is necessary to found the number of samples which has to be done in each stratum during future survey campaigns, a quantity named hereafter "total sample size". We consider two al ternatives to give the total sample size (both of BAS, GRTS and StRS):

- "mean Nopt": for each stratum, the mean on the six studied years optimal sample sizes are summed to have a total sample size in the whole bay;

- "max Nopt": retained total sample size is the maximal optimal sample size obtained for each stratum between the six studied years and sums them. 
A total of 1000 simulations are used to assess and compare these two total sample sizes for the virtual populations (one virtual population for each year of data). This gives the accuracy that would have been reached if these total sample size had applied in the field since 2003.

The total survey cost (TSC) is defined and computed using two parameters:

- (V) a survey variable cost dependent on the sample size (the costs of boat and grab rents, scientists and fishermen participation costs, etc.), established on expert knowledge at $\mathrm{V}=$ $80 €$ for this study.

- (F) a survey fixed cost (the costs of meetings to prepare the survey, material, data treatment, meetings to present the results to fishermen and administration, etc.), established on expert knowledge at $F=12500 €$ for this study.

The overall cost of the simulated designs is then calculated as follows:

(0) $\quad T S C=F+n \times V$,

where $\mathrm{n}$ is the number of samples.

\section{Results}

Total optimal sample sizes required to reach an accuracy of $10 \%$ per year in the whole bay differed between the assessed designs ; StRS requires almost twice GRTS or BAS optimal sample size for all the studied years (Fig. 3)

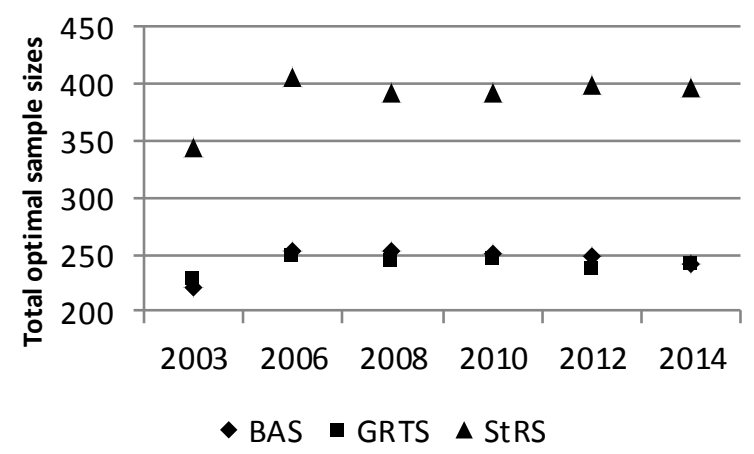

Fig. 3 : Total optimal sample size for the studied years in the whole Arcachon Bay for StRS, GRTS and BAS designs to achieve $10 \%$ of accuracy - Values are given in Supplementary information 
BAS and GRTS designs show comparable results for annual optimal sample size. Some variations are noticeable between years but all of them have a comparable optimal sample size with both designs. Tests of stationarity made on the three time series using autocorrelation and partial autocorrelation functions (ACF and PACF analysis - see graphs in supplementary materials) indicate that all functions are stationary. We also conduct kruskal-wallis rank sum test to prove that there are no significant differences between years for both of the sampling designs. Returned $p$-values of $R$ function kruskal.test() \{stats\} package are always higher than 0.72 , indicating no significant differences between total optimal sample sizes of both sampling designs throughout years. This result is of major importance for our intention to optimise the monitoring program. It means that, whatever the studied year, we can set a total sample size and $10 \%$ of accuracy on biomass and number of clams results will be achieved.

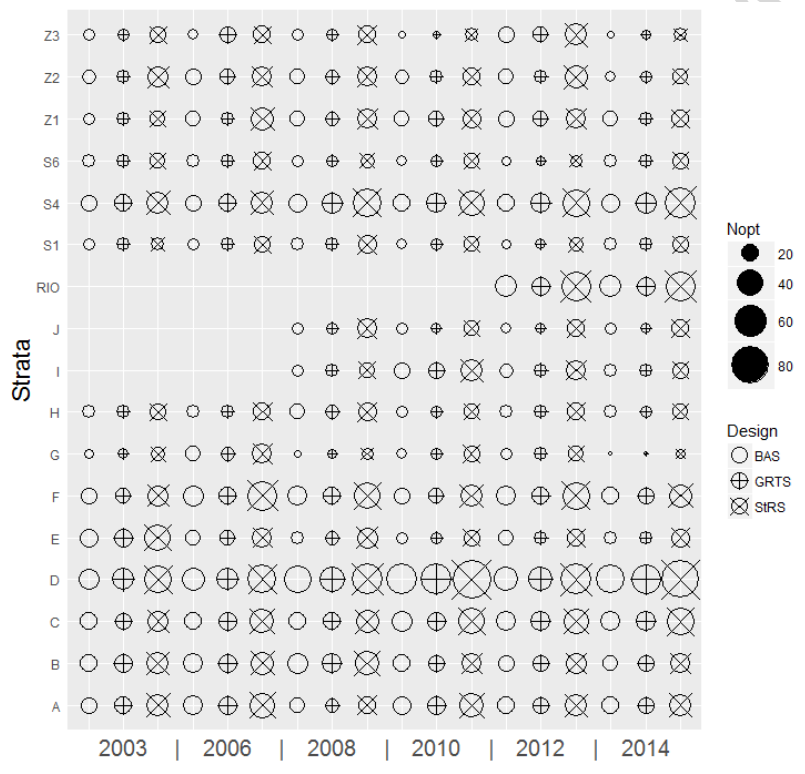

Fig. 4: Optimal sample size (Nopt) obtained by our methodology for the 17 strata for the 6 surveys. Bubbles sizes are proportional to optimal sample sizes. Empty bubbles show results for BAS design the ones with a " + " inside for GRTS and the ones with an " $x$ ", StRS.

Graphical comparison of optimal samples sizes for all strata is made using bubble plot (Fig. 4) : StRS always needs higher number of samples than GRTS and BAS to achieve $10 \%$ of accuracy in the results 
at the stratum scale (paired Wilcoxon tests between GRTS and StRS and then between BAS and StRS indicate that StRS is significantly different from GRTS and BAS; $p$-values $<2.2 \mathrm{e}-16)$. GRTS and BAS results are similar (paired Wilcoxon tests indicate a non-significant difference; $p$-value $=0.07909$ ), for some strata GRTS needs fewer samples than BAS and sometimes it is BAS that needs fewer than GRTS.

Overall, optimal sample sizes found for same strata are more or less equal among years.

Table 1 : "mean Nopt" and "max Nopt" total sample sizes with both of the survey designs (BAS, GRTS and StRS) and the approximation of their cost if they would be used on field.

\begin{tabular}{|l|l|l|l|l|}
\hline \multirow{2}{*}{ Design } & \multicolumn{2}{|l|}{ Mean Nopt } & Max Nopt \\
\cline { 2 - 5 } & Total sample size & Overall cost (in $€$ ) & Total sample size & Overall cost (in €) \\
\hline BAS & 292 & 35860 & 363 & 41540 \\
\hline GRTS & 287 & 35460 & 347 & 40260 \\
\hline StRS & 482 & 51060 & 633 & 63140 \\
\hline
\end{tabular}

There are big differences between BAS / GRTS and StRS total sample size and between prices (Table 1). BAS and GRTS total sample sizes and overall cost are widely lower than StRS ones. BAS would cost $30 \%$ and GRTS would cost 31\% less than StRS if the Mean Nopt" sample size would be used (and respectively $33 \%$ and $35 \%$ for "max Nopt"). 

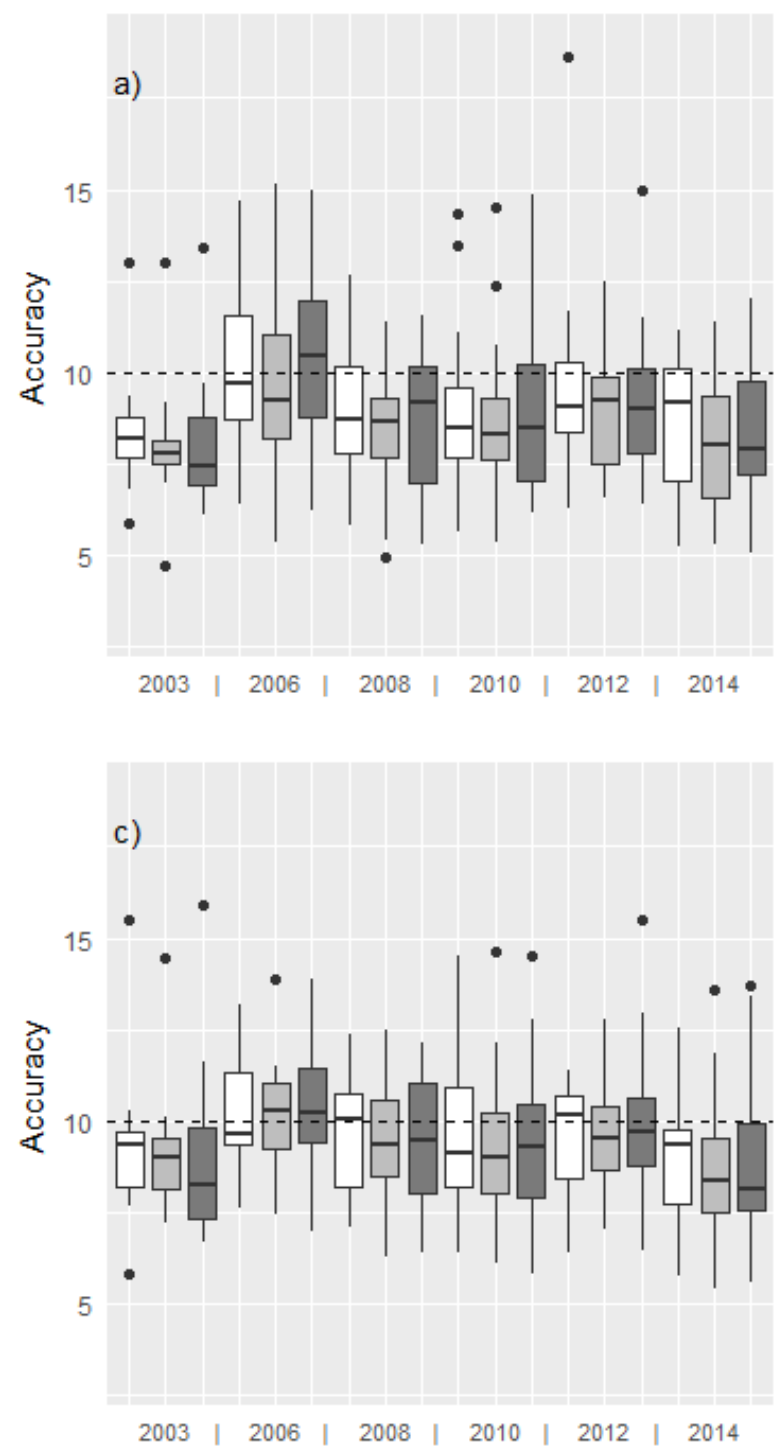

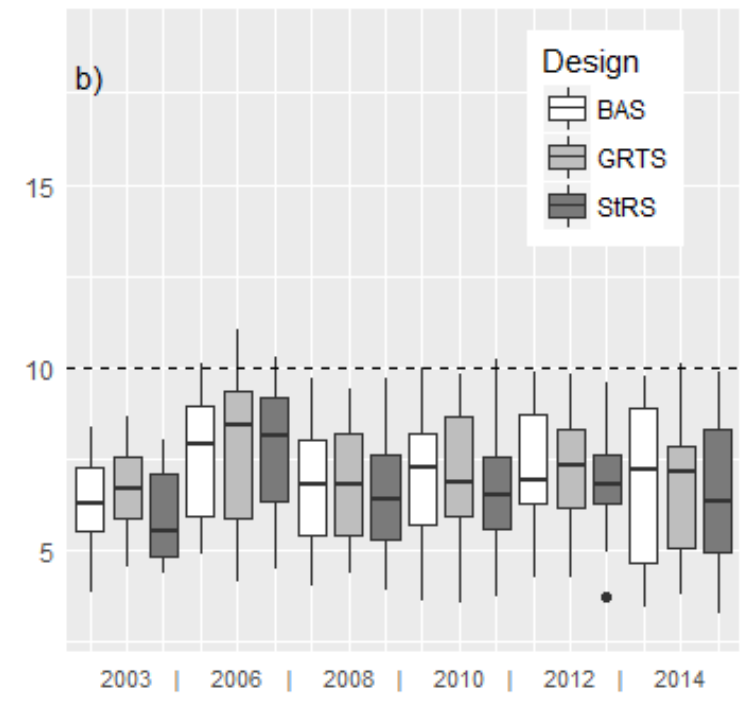

d)

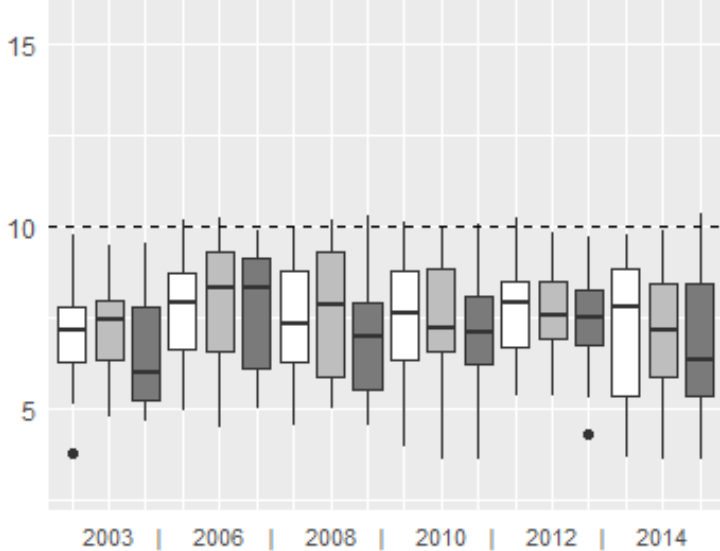

Fig. 5 : Box-plots of reached accuracy for all strata for: a) biomass with the "mean Nopt" total sample size, b) biomass with the "max Nopt" total sample size, c) abundance with the "mean Nopt" total sample size and d) abundance with the "max Nopt" total sample size - 1000 simulations.

If "max Nopt" and "mean Nopt" sample sizes are used, almost all the median are under the targeted level of $10 \%$ of accuracy (fig. 5). With "max Nopt" median level of accuracy are far under this targeted level. Both of these sample sizes are associated with few inter-annual variations in accuracy results.

\section{Discussion:}

There are two critical aspects to take into account when surveying an animal population: spatial variation in animal abundance and species detectability (MacKenzie 2006; Royle and Dorazio 2008). 
Clams do not have the capacity to escape during the survey and all the sediment of all the samples had been sifted: hence, one can assume that detectability denoted " $p$ " is almost maximal $(p=1)$. Thus, it can be considered that our data only account for clam spatial variation and not for survey method non-detection. The multi-seasonal database allows to also considering clam's patches temporal variation.

This simulation study convincingly demonstrates that GRTS and BAS perform nearly twice better than StRS for Arcachon Bay manila clam long term monitoring, confirming and extending thus the results published for the GRTS-only design and on the basis of one-year study (Kermorvant et al. 2017). For all the studied years, GRTS and BAS always need fewer sample points to achieve the same accuracy than StRS. This means that, years after years, these spatially sampling designs perform better in presence on spatial variation of clam's estimates and so are more cost-effective than simple random sampling. There is statistically no difference between using GRTS or BAS; sometimes GRTS needs fewer samples and sometimes it is BAS. Otherwise, we have shown that GRTS, BAS and StRS achieve good performances with few inter-annual variations in accuracy for this population. This indicates that temporal variation of clam's abundance and biomass does not have any noticeable effect on the performance of these sampling designs. This characteristic allows us providing "total sample sizes" which integrates both spatial and temporal heterogeneity of manila clam population. In terms of field conveniences, it indicates that we can set a same number of samples by strata for all the future campaigns and reach the targeted accuracy in population estimates.

Three accuracy levels (i.e. $5 \%, 10 \%$ and $20 \%$ ) were assessed in our simulation study but only the $10 \%$ level is presented in this paper to avoid overloading figures. Results for $5 \%$ and $20 \%$ are similar and the patterns are consistent with this $10 \%$ level (see Supplementary Information). The ability of GRTS and BAS to provide a spatially balanced scheme certainly has a role in their capacity to deal correctly with the spatially structured population of manila clams. Indeed, Christianson and Kaufman (2016) showed that sample spacing is a key factor for a design which has to bring a good estimation in presence of spatial variation. Also, the efficiency of a survey strategy is highly related to its space- 
filling characteristics (Rajabi and Ataie-Ashtiani 2014). A recent study, although limited to comparing two designs and not incorporating advanced survey techniques, highlighted that systematic survey designs could be superior than simple random design for selecting samples in clustered populations (McGarvey et al. 2016). Several other works show also that there is advantage in using a spatially balanced design when the response has spatial trend too (Stevens and Olsen 2004; Theobald et al. 2007; Grafström et al. 2012; Grafström 2012; Grafström and Lundström 2013; Robertson et al. 2013) . Results of our study further highlight the importance of taking into account spatial and temporal variations in the choice of sampling design for the optimisation of monitoring programs of spatial and temporal structured populations.

In a practical point of view, if StRS is still used during the future campaign in Arcachon bay with our sample size "mean Nopt", the price of the field survey will be the same than before $(\approx 50000 €)$; but with $10 \%$ of accuracy reached in both strata instead of an accuracy highly variable between both of them. The use of GRTS or BAS could advantageously reduce the price of future surveys of approximately $30 \%$ (dropping the total cost to ca $14000 €$ ). The price depends also on the used sample size: "mean Nopt" costs $5000 €$ less for BAS and GRTS than "max Nopt".

The main goal of our study was to prove that local monitoring programs could be optimised. For this, we had to found the more performing sampling design for manila clam's monitoring, and to propose a sample size which can be applied in all the futures field surveys of clam monitoring. Even if using "max Nopt" ensures an accuracy of the results far lower than $10 \%$, we suggest using instead "mean Nopt" with GRTS or BAS. The main rationale behind this proposal lies in the fact that i/ "mean Nopt" is sufficient to achieve an accuracy of nearly $10 \%$ for all strata, and ii/ it is less expensive than "max Nopt". Whilst we succeed at demonstrating that local monitoring programs could be optimised, this study remains a simulation study where the percentage of accuracy obtained is the mean of 1000 simulations (with an associated variance). In the field, it will obviously not be possible to lead 1000 replicates of the chosen sample size, and consequently (due to the random property of sampling designs) the real accuracy might not be exactly $10 \%$. 
We know that accuracy will not be exactly $10 \%$ for all the strata and all the years but this optimisation solution appears as the most logical trade-off between lowering the campaign costs and keeping a good accuracy in the results. Nonetheless, to stick to the reality of true needs, these results will have to be explained to professional clam fishermen. Even if they are already aware of this methodological reflexion, it will be mandatory to detail the pros and cons and make sure that they are convinced of the reliability of the survey if we make changes. For a successful collaboration, it is indeed essential that they understand and approve these methodological improvements. Thanks to GRTS or BAS, campaign costs can be lowered under $50000 €$ keeping a "good" accuracy in clams abundance and biomass, allowing for a continuous assessment of manila clam stock in Arcachon bay, and avoiding thus any other problematic break in the temporal series of this data set.

Nonetheless, despite great potential of GRTS in spatially balanced surveys of natural resources, it is restricted to a two-dimensional space and has no obvious extension to a higher dimension space. Theobald et al. (2007) and Grafström (2012) proposed several refinement or variation on GRTS, respectively called reversed randomized quadrant-recursive raster (RRQRR) theoretically possible in three-dimensional space, and spatially correlated Poisson survey (SCPS). BAS was also developed to allow a spatial balancing of samples in a multidimensional scale. Our study is the first ever in which BAS was used to optimise a monitoring design, demonstrating also that it performs as well as GRTS. Its promising results in two dimensions and its ability to perform spatial balance in more than two dimensions let us think that BAS will be very more relevant than GRTS for future surveys optimisation.

\section{Conclusion}

This study highlights that spatially balanced designs performs better than the simple random sampling to deal with the patchily distribution of manila clam population in Arcachon bay. But, we have shown that they also behave appropriately with the temporal variation of manila clam spatial structure. We argue that it is now possible to define a sample size by strata that could be done for all future campaigns to achieve a given level of accuracy in the results. Results show that, even if 
spatially balanced designs are more cost effective, trade-off between achieving accuracy and survey price are always to be considered.

We convincingly emphasize a positive effect of adopting such advanced spatially balanced design in avoiding any potential temporal breaks following money short-coming (such as the one occurring during 2014 when no manila clam monitoring campaign in Arcachon bay could be done because of fund lack). In the past, one field campaign used to cost at least $50000 €$ and given strata sizedependent sampling effort, accuracy on the results proved to be different between strata. Now, benefiting from the outputs of our study, we advocate that changing the sampling design and using a non strata size-dependent sampling effort, the campaign should potentially cheaper, with a gain of $14000 €$ (i.e. $\approx-30 \%$ ) if a mean of $10 \%$ of accuracy in each strata is to be achieved. This would undeniably lead to provide a rigorous dynamic image of the clam population in the whole bay and help thus fishermen to define good sustainable management for their resource, on a continuous basis.

With this work, we hope demonstrating efficiently that not only long term monitoring programs can be optimised but this change in sampling procedure is easily transferable to be reproducible in other similar contexts where resources have to be surveyed on a continuous dynamic basis. If using spatially balanced sampling design can reduce by $30 \%$ the price of Arcachon bay manila clams monitoring, using it elsewhere in other similar socio-economic context should also profitably reduce the long term monitoring costs. To extend the benefits of this study to a larger scale (European for example) the concept of master sample (van Dam-Bates et al. 2018) could be assessed.

Eventually, to be totally generic, it remains necessary to test other spatially balanced sampling designs such as local pivotal method (Grafström et al. 2012). The main reason why we choose to assess performances of BAS, and why we believe in its potential for the future, is because it permits to extend the spatial balancing of the samples to more than two dimensions. BAS performance was never tested to optimise a monitoring programs, and now that we know that BAS is relevant for this ones in two dimensions ( $x$ and $y$ coordinates), we have to found one (or more) explicative variable(s) 
(for example sedimentology or water circulation in the bay) of manila clam dispersion in Arcachon Bay and use it as a third (or more) dimension. This could lead to an even more cost-effective sampling design.

\section{Acknowledgments:}

Data were collected in the context of the Manila clam monitoring program financed by the French institute Ifremer, European grants (IFOP -instrument Financier d'Orientation de la Pêche; and FEP Fonds Européens pour la Pêche), the French government (MEEM - Ministère de l'Environnement, de l'Energie et de le Mer), Aquitaine Regional Council, Gironde General Council and professional fishing organizations. This work was supported by Ifremer's scientific direction within the framework of site policy grants (DESCARTES 2 project) aiming to reinforce collaborations between Ifremer and regional academic partners. This work was also supported by “Communauté d'Agglomération Pays Basque Euskal Hirigune Elkargoa" through a thesis grant. 
Abi N, Moradi M, Salehi M, et al (2017) Application of Balanced Acceptance Sampling to an Intertidal Survey. J Landsc Ecol 10:96-107

Astorga MP (2014) Genetic considerations for mollusk production in aquaculture: current state of knowledge. Front Genet 5:435

Bald J, Borja Á (2001) Estudio de los recursos de almeja y berberecho en Mundaka y Plentzia (19982000). Inf.Tec.Gob.Vas. 93:80

Bald J, Borja A (2005) Estudio del estado de los recursos de almeja y berberecho en los estuarios Mundaka, Plentzia y Txingudi (1998-2004)). Inf.Tec.Gob.Vas. 105:76

Berthou P, Huet J, Noel P, et al (1997) Etude de la pêcherie de palourdes du Golfe du Morbihan. Ifremer, France

Bidegain G, Bárcena JF, García A, Juanes JA (2015) Predicting coexistence and predominance patterns between the introduced Manila clam (Ruditapes philippinarum) and the European native clam (Ruditapes decussatus). Estuar Coast Shelf Sci 152:162-172

Borja Á, Bald J (2000) Estado de los recursos marisqueros del País Vasco en 1998-1999 (con especial atención a almeja y berberecho). Informes Técnicos (Departamento de Agricultura y Pesca, Gobierno Vasco). 86:78

Brown JA, Robertson BL, McDonald T (2015) Spatially Balanced Sampling: Application to Environmental Surveys. Spat Stat Conf 2015 27:6-9. doi: 10.1016/j.proenv.2015.07.108

Caill-Milly N, Bobinet J, Lissardy M, et al (2008) Campagne d'évaluation du stock de palourdes du bassin d'Arcachon-Année 2008

Caill-Milly N, de Casamajor M-N, Lissardy M, et al (2003) Évaluation du stock de palourdes du bassin d'Arcachon-Campagne 2003

Caill-Milly N, Duclercq B, Morandeau G (2006) Campagne d'évaluation du stock de palourdes du bassin d'Arcachon-Année 2006. Ifremer, France

Carlton JT, Thompson JK, Schemel LE, Nichols FH (1990) Remarkable invasion of San Francisco Bay (California, USA), by the Asian clam Potamocorbula amurensis. I. Introduction and dispersal. Mar Ecol Prog Ser 66:81-94

Chiarucci A, Enright NJ, Perry GLW, et al (2003) Performance of nonparametric species richness estimators in a high diversity plant community. Divers Distrib 9:283-295. doi: 10.1046/j.1472-4642.2003.00027.x

Christianson DS, Kaufman CG (2016) Effects of sample design and landscape features on a measure of environmental heterogeneity. Methods Ecol Evol 7:770-782. doi: 10.1111/2041-210X.12539

Cox DD, Cox LH, Ensor KB (1997) Spatial sampling and the environment: some issues and directions. Environ Ecol Stat 4:219-233. doi: 10.1023/A:1018578513217

Dang C, De Montaudouin X, Bald J, et al (2009) Testing the enemy release hypothesis: trematode parasites in the non-indigenous Manila clam Ruditapes philippinarum . Hydrobiologia 630:139-148 
Dang C, De Montaudouin X, Binias C, et al (2013) Correlation between perkinsosis and growth in clams Ruditapes spp. Dis Aquat Organ 106:255-265

Davidson K, Dudas SE (2016) Microplastic Ingestion by Wild and Cultured Manila Clams (Venerupis philippinarum) from Baynes Sound, British Columbia. Arch Environ Contam Toxicol 71:147156. doi: 10.1007/s00244-016-0286-4

Defeo O (2003) Marine Invertebrate Fisheries in Sandy Beaches: An Overview. J Coast Res 56-65

Denadai MR, Cecília Z. Amaral A, Turra A (2005) Along-and across-shore components of the spatial distribution of the clam Tivela mactroides (Born, 1778)(Bivalvia, Veneridae). J Nat Hist 39:3275-3295

Dugan JE, McLachlan A (1999) An assessment of longshore movement in Donax serra Röding (Bivalvia: Donacidae) on an exposed sandy beach. J Exp Mar Biol Ecol 234:111-124. doi: 10.1016/S0022-0981(98)00145-2

Grafström A (2012) Spatially correlated Poisson sampling. J Stat Plan Inference 142:139-147. doi: 10.1016/j.jspi.2011.07.003

Grafström A, Lundström NL (2013) Why well spread probability samples are balanced. Open J Stat 3:36-41

Grafström A, Lundström NL, Schelin L (2012) Spatially balanced sampling through the pivotal method. Biometrics 68:514-520

Gray CA (2016) Tide, time and space: Scales of variation and influences on structuring and sampling beach clams. J Exp Mar Biol Ecol 474:1-10. doi: 10.1016/j.jembe.2015.09.013

Gray CA, Johnson DD, Reynolds D, Rotherham D (2014) Development of rapid sampling procedures for an exploited bivalve in the swash zone on exposed ocean beaches. Fish Res 154:205-212. doi: 10.1016/j.fishres.2014.02.027

Jackson AL, Broderick AC, Fuller WJ, et al (2008) Sampling design and its effect on population monitoring: How much monitoring do turtles really need? Biol Conserv 141:2932-2941. doi: 10.1016/j.biocon.2008.09.002

James RJ, Fairweather PG (1996) Spatial Variation of Intertidal Macrofauna on a Sandy Ocean Beach in Australia. Estuar Coast Shelf Sci 43:81-107. doi: 10.1006/ecss.1996.0058

Jensen A, Humphreys J, Caldow R, et al (2004) Naturalization of the Manila clam (Tapes philippinarum), an alien species, and establishment of a clam fishery within Poole Harbour, Dorset. J Mar Biol Assoc UK 84:1069-1073

Katz J, Moyle PB, Quiñones RM, et al (2013) Impending extinction of salmon, steelhead, and trout (Salmonidae) in California. Environ Biol Fishes 96:1169-1186

Keinath DA, NRA BC (2016) Bat population monitoring of Bighorn Canyon National Recreation Area: 2015 progress report. 3. pp

Kermorvant C, Caill-Milly N, D'Amico F, et al (2017) Optimization of a survey using spatially balanced sampling: a single-year application of clam monitoring in the Arcachon Bay (SW France). Aquat Living Resour 30:37 
Lazarina M, Kallimanis AS, Pantis JD, Sgardelis SP (2014) Linking species richness curves from noncontiguous sampling to contiguous-nested SAR: An empirical study. Acta Oecologica 61:2431. doi: 10.1016/j.actao.2014.10.001

Le TC, Kang H-S, Hong H-K, et al (2015) First report of Urosporidium sp., a haplosporidian hyperparasite infecting digenean trematode Parvatrema duboisi in Manila clam, Ruditapes philippinarum on the west coast of Korea. J Invertebr Pathol 130:141-146

Li M, Xu T, Zhou Q (2012) Development of Python-based ArcGIS Tools for Spatially Balanced Forest Sampling Design. Atlantis Press, pp 939-942

MacKenzie DI (2006) Occupancy estimation and modeling: inferring patterns and dynamics of species occurrence. Academic Press

McGarvey R, Burch P, Matthews JM (2016) Precision of systematic and random sampling in clustered populations: habitat patches and aggregating organisms. Ecol Appl 26:233-248

McLachlan A, Dugan JE, Defeo O, et al (1996) Beach clam fisheries. Oceanogr Mar Biol Annu Rev 34:163-232

Paillard C, Allam B, Oubella R (2004) Effect of temperature on defense parameters in Manila clam Ruditapes philippinarum challenged with Vibrio tapetis. Dis Aquat Organ 59:249-262

Park K-I, Choi K-S (2001) Spatial distribution of the protozoan parasite Perkinsus sp. found in the Manila clams, Ruditapes philippinarum, in Korea. Aquaculture 203:9-22

Pitel M, Savina M, Fifas S, Berthou P (2004) Evaluations locales des populations de bivalves dans le golfe de normand breton. Résultats de la campagne BIVALVES2002 - IFREMER. 6-7

Pranovi F, Franceschini G, Casale M, et al (2006) An Ecological Imbalance Induced by a Non-Native Species: The Manila Clam in the Venice Lagoon. Biol Invasions 8:595-609. doi: 10.1007/s10530-005-1602-5

R Core Team (2014) R: A language and environment for statistical computing. R Foundation for Statistical Computing, Vienna, Austria

Rajabi MM, Ataie-Ashtiani B (2014) Sampling efficiency in Monte Carlo based uncertainty propagation strategies: application in seawater intrusion simulations. Adv Water Resour 67:46-64

Robertson B, Brown J, McDonald T, Jaksons P (2013) BAS: Balanced acceptance sampling of natural resources. Biometrics 69:776-784

Robertson B, McDonald T, Price C, Brown J (2017) A modification of balanced acceptance sampling. Stat Probab Lett

Royle J, Dorazio R (2008) Hierarchical modelling and inference in ecology. Á Acad Press N Y

Sanchez F, Caill-Milly N, De Casamajor Marie-Noelle LM (2012) Campagne d'évaluation du stock de palourdes du bassin d'Arcachon. Ifremer, France

Sanchez F, Caill-Milly N, Lissardy M, et al (2010) Campagne d'évaluation du stock de palourdes du bassin d'Arcachon. Ifremer, France 
Sanchez F, Caill-Milly N, Lissardy M, Bru N (2014) Campagne d'évaluation de stock de palourdes du bassin d'Arcachon. Ifremer, France

Smith AN, Anderson MJ, Pawley MD (2017) Could ecologists be more random? Straightforward alternatives to haphazard spatial sampling. Ecography. doi: 10.1111/ecog.02821

Stevens DL, Olsen AR (2004) Spatially balanced sampling of natural resources. J Am Stat Assoc 99:262-278

Stevens DL, Olsen AR (1999) Spatially restricted surveys over time for aquatic resources. J Agric Biol Environ Stat 415-428

Stevens DL, Olsen AR (2003) Variance estimation for spatially balanced samples of environmental resources. Environmetrics 14:593-610

Talley DM, Talley TS, Blanco A (2015) Insights into the establishment of the Manila clam on a tidal flat at the southern end of an introduced range in southern California, USA. PloS One 10:e0118891

Theobald DM, Stevens Jr DL, White D, et al (2007) Using GIS to generate spatially balanced random survey designs for natural resource applications. Environ Manage 40:134-146

van Dam-Bates P, Gansell O, Robertson B (2018) Using balanced acceptance sampling as a master sample for environmental surveys. Methods Ecol. Evol.

Wekell JC, Gauglitz EJ, Bamett HJ, et al (1994) Occurrence of domoic acid in washington state razor clams (Siliqua patula) during 1991-1993. Nat Toxins 2:197-205. doi: 10.1002/nt.2620020408

Yoccoz NG, Nichols JD, Boulinier T (2001) Monitoring of biological diversity in space and time. Trends Ecol Evol 16:446-453

Yu H, Jiao Y, Su Z, Reid K (2012) Performance comparison of traditional sampling designs and adaptive sampling designs for fishery-independent surveys: a simulation study. Fish Res 113:173-181

Zhao G, Hoffmann H, Yeluripati J, et al (2016) Evaluating the precision of eight spatial sampling schemes in estimating regional means of simulated yield for two crops. Environ Model Softw 80:100-112 
Highlights:

- Long term monitoring program at local scale are mandatory for resource management but often too expensive to undertake.

- For the example of manila clams resource in Arcachon bay, each campaign price can be lowered by $30 \%$ only in using spatially balanced sampling design instead of simple random sampling.

- More than lowering the survey price, wanted accuracy in the results can be fixed a priori.

- BAS sampling design, never compared to other sampling designs in real data previously perform very well. 